\title{
Who needs and continues to need paediatric palliative care? An evaluation of utility and feasibility of the Paediatric Palliative Screening scale (PaPaS)
}

\author{
Poh Heng Chong ${ }^{1 *} \mathbb{D}$, Janice Soo ${ }^{2}$, Zhi Zheng Yeo ${ }^{1}$, Raymond Qishun $\mathrm{Ang}^{1}$ and Celene Ting ${ }^{1}$
}

\begin{abstract}
Background: While the populations of children who can benefit from paediatric palliative care (PPC) have been broadly defined, identifying individual patients to receive PPC has been problematic in practice. The Paediatric Palliative Screening scale (PaPaS) is a multi-dimensional tool that assesses palliative care needs in children and families to facilitate timely referrals. This study evaluates its use to manage new referrals and ongoing review of patients receiving home-based PPC in Singapore.
\end{abstract}

Methods: Using a retrospective cohort study design, 199 patients admitted to receive PPC via clinician screening were scored using PaPaS. Eighty-four patients in two groups were scored again at one of two following milestones: one-year service continuation mark or point of discharge before a year. Accuracy measures were compared against clinical assessment.

Results: $96.98 \%$ of patients scored 15 and above on admission (indicating need for PPC). Patients assessed at following milestones were effectively stratified; those who continued to receive service after 1 year scored significantly higher $(M=19.23)$ compared to those who were discharged within a year $(M=7.86)$. Sensitivity and specificity for PaPaS were calculated at 82.54 and 100\% respectively. Overall congruence with clinician-based decisions supports the utility of PaPaS as a screening tool in PPC. Recommendations to improve the scale further are proposed.

Conclusion: The PaPaS is a practical screening tool that signposts PPC needs within the clinical setting. This facilitates early referrals to PPC, without having to specify individual prognoses that are often uncertain. Other benefits include optimised continuity of care and implications for resource allocation.

Keywords: Paediatric palliative care, Home hospice, Needs assessment, Screening tool, Admission

\section{Background}

As part of a growing movement to improve the care of seriously-ill children, Paediatric Palliative Care (PPC) services around the world face a myriad of challenges. Other than securing sustainable funding [1,2], efforts to promote service access, both in the patient community and among healthcare providers, have been described [3-5]. In addition, at service transition after a referral to

\footnotetext{
* Correspondence: pohhengc@hcahospicecare.org.sg

'HCA Hospice Care, 705 Serangoon Road, \#03-01 Block A @ Kwong Wai Shiu Hospital, Singapore 328127, Singapore

Full list of author information is available at the end of the article
}

PPC has been made, good communication between healthcare professionals is critical [6], not only for access, but also continuity of care and patient safety [7].

While ethos and approaches are similar, the scope of work in adult and paediatric palliative care can differ [8]. In contrast to most life-threatening illness such as cancers in the adult-setting, both children with lifethreatening and life-limiting illness (henceforth combined under 'life-shortening illness') present a wide variety of diagnoses. These are broadly categorised into four typologies that include congenital anomalies, metabolic diseases, neurological conditions and conditions

(c) The Author(s). 2020 Open Access This article is distributed under the terms of the Creative Commons Attribution 4.0 International License (http://creativecommons.org/licenses/by/4.0/), which permits unrestricted use, distribution, and reproduction in any medium, provided you give appropriate credit to the original author(s) and the source, provide a link to the Creative Commons license, and indicate if changes were made. The Creative Commons Public Domain Dedication waiver (http://creativecommons.org/publicdomain/zero/1.0/) applies to the data made available in this article, unless otherwise stated. 
that are non-progressive, like cerebral palsy [9]. In fact, the cohort with oncological diagnoses number just around $20-30 \%[10,11]$ in most PPC patient census.

Average length of service in PPC is generally longer than that in adult palliative care [12]. Disease trajectories are often uncertain and can differ widely, even between children with the same diagnosis; individual survival can vary from hours to more than 20 years [13, 14]. Heterogeneity in qualifying medical conditions and overall longer survivals are hallmarks of PPC that together increase the complexity in service planning and implementation [15].

Given all the above considerations, eligibility for PPC is necessarily needs-based rather than prognosis-driven; and an objective tool that clearly defines the patient or family with PPC needs is indicated [16]. In addition to accounting for complex needs and longer length of service, such a tool can help address concerns about service sustainability by providing justification for allocating scarce resources between children with varying needs. Finally, a structured and standardised approach to case referrals can also improve communication between providers at point of referral or handover.

Internationally, the populations of children who can benefit from PPC have been defined [17, 18]. Yet, referrals are often made late or not at all [19]. Though the 'surprise question' used effectively in the adult setting has been found to be equally sensitive as a prognostic tool in children [20], it is still inadequate as a screening tool within the PPC ethos of holistic family-centred care that starts from diagnosis.

The Spectrum of Children's Palliative Care Needs has been conceived to incorporate exactly these multidimensional elements, grouping children who are eligible for PPC into five prognostic-based categories with distinct care needs [21], though these needs have not been explicitly specified. This framework remains problematic, with participants in an early validation exercise commenting that categorisation still needed their own consolidated assessments that included: clinical symptoms, treatment outcomes, dependency indicators, psychosocial factors, and patient/carer priorities.

One promising tool for screening patients for PPC needs is the Paediatric Palliative Screening scale (PaPaS) [22]. The PaPaS targets timely referrals to PPC through identifying (screening for) children with palliative care needs. It consists of a series of questions in five domains, which are almost the same domains described in the Spectrum of Needs framework [21]. Each question is weighted and assigned a score depending on the response [23]. The total score is then used to stratify patients into different courses of action; a score of 15 and above indicates that PPC could be initiated [22, 23].

Other than the original authors who had conceived and validated the $\mathrm{PaPaS}$, there have not been published reports of its application in other settings. Prior to its implementation in local policy and practice, we performed an evaluation of the utility and feasibility of the $\mathrm{PaPaS}$ as an admission-screening tool within a homebased PPC service. Besides admission, we also explored its use in relation to continuation of $\mathrm{PPC}$, such as reassessment after one year. Our findings, experience and recommendations are reported in this paper.

The primary objective of this study is to assess the utility and feasibility of PaPaS as a referral screening tool to identify paediatric patients who may require PPC. The secondary objective evaluates the utility of $\mathrm{PaPaS}$ to determine continuation of PPC after one year.

\section{Methods}

Design

A non-interventional, retrospective cohort study design was adopted, using data collected as part of standard service provision. For the primary objective, action plans recommended by the $\mathrm{PaPaS}$ were compared against those by clinician assessment, the common standard to determine patient admissions. For the secondary objective, we hypothesise that $\mathrm{PaPaS}$ can distinguish between patients suitable for interim discharge and those who require continuation of PPC beyond the first year. To this end, two groups of patients - those who continued to received PPC after one year and those discharged within a year-were assessed using the $\mathrm{PaPaS}$ a second time based on their respective end-points, and their scores compared.

\section{Setting}

The patient population studied received home-based PPC from a specialist paediatric palliative care service in Singapore. The service is nested within the nation's largest home hospice service, which provides palliative and supportive care for patients at home. A team of eight multi-disciplinary healthcare providers is dedicated solely to the care of paediatric patients.

All patients admitted have life-shortening conditions as described by Association for Children's Palliative Care and the Royal College of Paediatric and Child Health [9]. Like similar services elsewhere [6, 11], the team serves a majority of young persons with noncancer diagnoses (80\% of cases). New referrals come mainly from tertiary children hospitals that are government funded, with occasional referrals from private paediatricians or oncologists.

Pre-PaPaS, referrals were screened for admission based on the clinical judgement of a single physician trained in paediatric palliative medicine. As part of normal workflow, patients were also reviewed periodically afterwards at multi-disciplinary team (MDT) meetings, for service continuation or interim discharge. 


\section{Data collection}

The study included patients admitted into the service between Apr 2012 and July 2016. No age limits were set. Data was extracted from electronic records in the team's patient management system.

Scoring was determined by JS, who reviewed patient records at the appropriate time-points, and chose the responses that best fitted descriptions in the records. Information relevant to the $\mathrm{PaPaS}$ were never explicitly requested from referring sources before. Hence, a flexible approach to assigning scores was adopted; for each patient, JS studied multiple sources of information (e.g. referral forms, discharge summaries from referring institutions, and notes from internal medical records) to impute scores. The scores were corroborated by $\mathrm{PHC}$, who scored a sub-sample of 20 randomly selected patients ( $10 \%$ of sample) to ensure agreement. Where information required for scoring items in the $\mathrm{PaPaS}$ was insufficient or missing, these patients were excluded from analysis. A referral form may have no mention of 'symptom intensity' or 'difficulty of symptom control', which prevents scoring of one item in the original scale [22]. This patient for example would be excluded from our analysis.
For the second assessment, two groups of patients were identified within the sample: patients who received PPC for more than 1 year, and patients who were discharged before 1 year. PaPaS scores were imputed a second time for individual patients using information either at the one-year mark or at point of discharge. Patients not belonging to either groups were excluded. Sensitivity and specificity values for the screening scale at these subsequent milestones were determined.

All scores were tabulated using Microsoft Excel 2016; statistical analyses (e.g. Student t-test and Chi-squared tests) and presentation of distributions (box-plots) were done with STATA 15. The STARD guidelines is referenced in structuring this report [24].

\section{Results}

Figure 1 details the flowchart for the study population. Two hundred twenty-eight patients were referred for PPC at home between April 2012 and July 2016. Twenty-nine patients (12.71\%) were excluded due to insufficient or missing information; the First Assessment scored 199 patients (at point of referral). Eighty-four patients were included in the Second Assessment involving

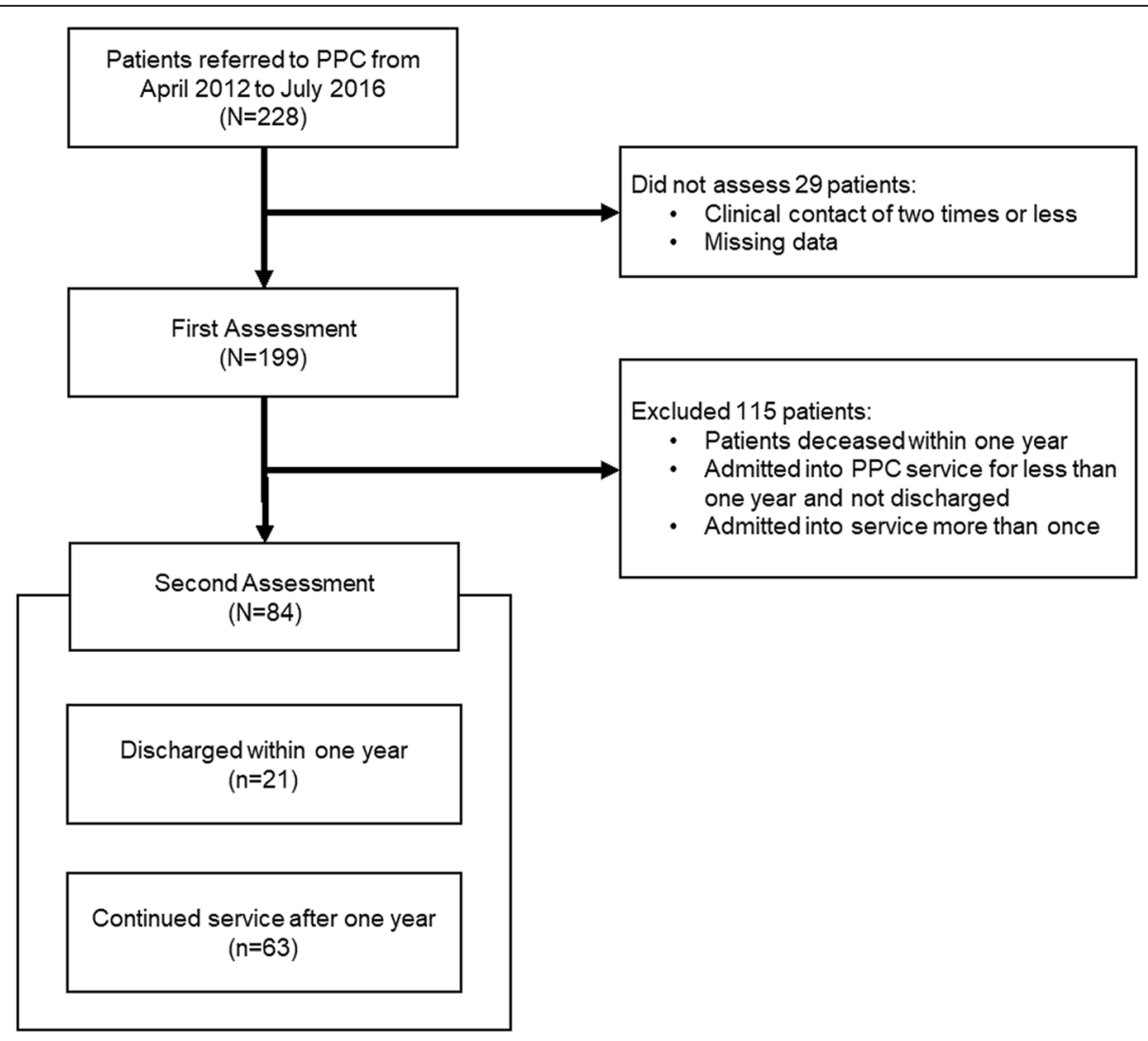

Fig. 1 Study population flowchart 
Table 1 Demographics of patients at First Assessment $(N=199)$

\begin{tabular}{ll}
\hline Demographics & \\
\hline Age at referral & $12.6(12.2)$ \\
Median age in years (IQR) & 0 (1 day old) to 39.6 \\
Range of ages in years & 18 \\
Number of patients less than 1 year old & 141 \\
Number of patients between 1 and 19years old & 40 \\
Number of patients 19 years old or above & 40 \\
Gender & $84(42.2 \%)$ \\
Female (\%) & $115(57.8 \%)$ \\
Male (\%) & $57(28.6 \%)$ \\
Type of diagnosis & $142(71.4 \%)$ \\
Cancer (\%) & \\
Non-cancer (\%)
\end{tabular}

two groups; 115 patients were excluded for various reasons (listed in Fig. 1).

\section{First assessment}

Table 1 summarises the demographics of patients at First Assessment. Figure 2 shows the box-plot distribution of $\mathrm{PaPaS}$ scores for the First Assessment. Scores ranged from 10 to 32 points, with a mean score of 23.71 (SD: 4.43; Median score 25). One hundred ninety-three patients (96.98\%) scored 15 and above.

\section{Second assessment}

For the Second Assessment, 84 patients in two groups were reassessed with $\mathrm{PaPaS}$. Table 2 shows their demographics; there were no significant differences in age, gender, or diagnosis types between groups $(p>.05)$.

Table 3 shows the distribution of patients between groups, based on their PaPaS scores. We hypothesised that patients who scored $0-14$ on the PaPaS could be considered for discharge, while those who scored 15 and above eligible for continuation of PPC. For actual patients in the 'continued service' group, 52 scored above 15 points, whereas all discharged patients $(n=$ 21) scored less than 15. Compared against standard clinical assessment for discharge and service continuation, the $\mathrm{PaPaS}$ demonstrated a sensitivity of $82.54 \%$ and a specificity of $100 \%$. Patients who continued to receive PPC after one year had a significantly higher mean score compared to patients who were discharged within one year $(p<.001)$.

\section{Discussion}

To our knowledge, this is the first utility and feasibility study on the $\mathrm{PaPaS}$ - to screen patients for specialist PPC and make decisions to retain/discharge existing patients. Findings demonstrate that recommended action plans according to $\mathrm{PaPaS}$ scores were largely congruent with decisions made through case assessment, whether by a single clinician or MDT. Although this study was not aimed at validation, real patients' data were used to provide substantive support for the PaPaS's utility in identifying paediatric patients with palliative care needs $[17,18]$. By comparing imputed scores with actual events in practice (i.e. clinical decisions around acceptance of new referrals), some indication of criterion validity for the $\mathrm{PaPaS}$ is rendered.

The $\mathrm{PaPaS}$ demonstrates intrinsic benefits of transparency and reliability. An objective and standardised scoring system helps to overcome variation in referral patterns among paediatricians that stem from differential interpretations of what palliative care entails [25]. The checklist approach to screening for

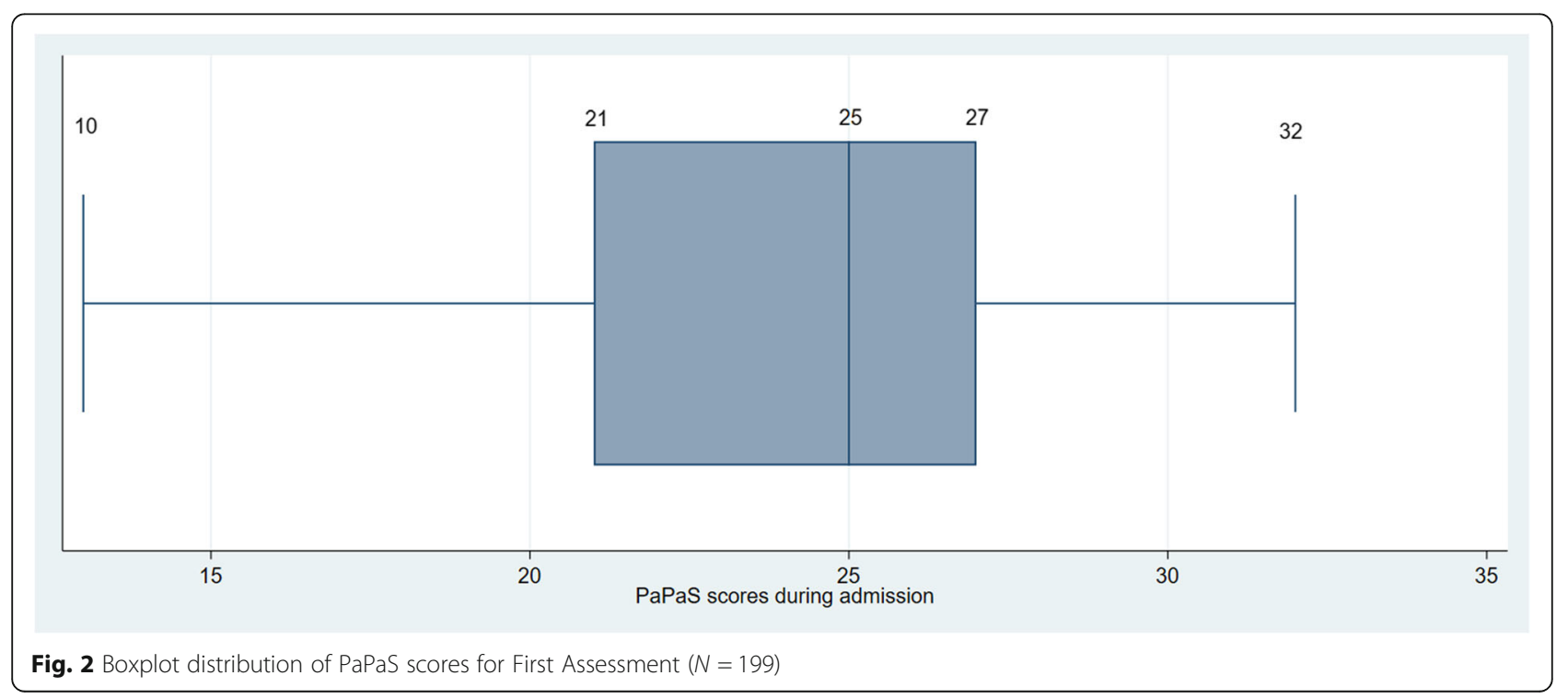


Table 2 Demographics of patients at Second Assessment $(N=84)$

\begin{tabular}{|c|c|c|}
\hline Demographics & Discharged $(\boldsymbol{n}=21)$ & Continued service $(\boldsymbol{n}=63)$ \\
\hline \multicolumn{3}{|l|}{ Age at referral ${ }^{a}$} \\
\hline Median age in years (IQR) & $15.8(10.3)$ & $12.6(11.4)$ \\
\hline Minimum age in days & 81 & 119 \\
\hline Maximum age in years & 30.2 & 34.1 \\
\hline \multicolumn{3}{|l|}{ Gender $^{b}$} \\
\hline Female (\%) & $8(38.1 \%)$ & $32(50.8 \%)$ \\
\hline Male (\%) & $13(61.9 \%)$ & $31(49.2 \%)$ \\
\hline \multicolumn{3}{|l|}{ Type of diagnosis ${ }^{c}$} \\
\hline Cancer (\%) & 0 & $1(1.6 \%)$ \\
\hline Non-cancer (\%) & $21(100 \%)$ & $62(98.4 \%)$ \\
\hline
\end{tabular}

${ }^{a}$ t-test found no significant difference in mean ages between the groups; $p>.05$

${ }^{b} \mathrm{X}^{2}$-test found no significant difference in gender between groups; $p>.05$

' Fisher's exact test found no significant difference in diagnosis between groups; $p>.05$

palliative care needs is also advocated by expert consensus in the adult setting [26]. Such a tool can potentially aid policy makers in evidence-based planning, resource allocation and cost-effective commissioning of new services [27]. However, some outliers may remain that still require case-by-case consideration using alternative approaches, such as individual assessments by a clinician who is familiar with the principles of PPC.

In some settings, practitioners may find $\mathrm{PaPaS}$ useful for the purpose of resource allocation; to identify patients who no longer require specialist PPC after a period of intensive case management [19]. With some modifications, $\mathrm{PaPaS}$ demonstrates potential not only as an assessment tool for planning intake, but also discharge from and continuation of PPC. Given uncertain trajectories and huge diversity in diagnoses over wide neurodevelopmental ages, some services can consider segmentation of patients and families for long-term service sustainability. The facility for temporary discharge from PPC while the child continues to consult primary physicians in tertiary institutions is one option. The PaPaS appears to support this exercise when indicated. In fact, since late 2017, the Ministry of Health in Singapore has adopted the $\mathrm{PaPaS}$ to determine eligibility for home-based PPC; it is administered both on admission, and assessment for service continuation at 1 year and every year thereafter.

Another key objective in this study is to explore feasibility aspects of the instrument. In the process of imputing scores for individual patients, several ways to improve its administration were identified. These observations and suggestions are summarised in Table 4 for users' consideration. A proposed new version of the scale is designed (Appendix) based on these comments.

\section{Implications}

With finite public health funding for PPC programmes, the $\mathrm{PaPaS}$ emerges as a tool that can systematically identify patients and families who will benefit from resource-intensive PPC at the specialist level. Widespread adoption of $\mathrm{PaPaS}$ may improve understanding of what PPC involves, resulting in timely referrals from paediatricians who may otherwise be unfamiliar with PPC or its service eligibility

Table 3 PaPaS scores at Second Assessment $(N=84)$

\begin{tabular}{lll}
\hline PaPaS scores (with suggested action) & Continued service $(\boldsymbol{n}=63)$ & Discharged $(\boldsymbol{n}=21)$ \\
\hline $\mathbf{0 - 1 4}$ (Not for PPC) & $11(17.46 \%)$ & $21(100 \%)$ \\
$\quad$ Number of patients (\% of column) & & 0 \\
$\mathbf{1 5}$ and above (For PPC) & $52(82.54 \%)$ & $7.86(2.39)$ \\
Number of patients (\% of column) & $19.25(4.74)$ &
\end{tabular}

${ }^{\mathrm{a}}$ Difference of mean scores between groups $=11.39(95 \% \mathrm{Cl}$ : 9.86-12.93); t-test: $p<.001$ 
Table 4 Domain-specific observations and comments for PaPaS for assessment of patients

\begin{tabular}{ll}
\hline Domain Item & Characteristics \\
\hline $\mathbf{1 . 1}$ Trajectory of disease and impact on daily & Stable \\
$\begin{array}{l}\text { activities of the child (in comparison with the } \\
\text { child's own baseline) (with reference to the last 4 } \\
\text { weeks) }\end{array}$ & $\begin{array}{l}\text { Slowly deteriorating without impact } \\
\text { on daily activities } \\
\text { Unstable; with impact on and } \\
\text { restriction of daily activities }\end{array}$ \\
& $\begin{array}{l}\text { Significant deterioration with severe } \\
\text { restriction of daily activities }\end{array}$ \\
$\mathbf{1 . 2}$ Increase of hospital admissions, (> 50\% within & No \\
3 months, compared to previous periods) & Yes
\end{tabular}

2.1 Treatment directed at the disease, (does not mean treatment of disease related complications, such as pain, dyspnoea or fatigue)

2.2 Burden of treatment, (Burden means side effects of treatment and additional burdens such as stay in hospital in the patient's or family's view)

3.1 Symptom intensity or difficulty of symptom control (over the last 4 weeks)

3.2 Psychological distress of patient related to symptoms

3.3Psychological distress of parents or family related to symptoms and suffering of the child

.... is curative

... controls disease and prolongs life with good quality of life a positive effect on quality of life

... does not control and has no effect on quality of life

No or minimal burden or no treatment is envisioned

Low level of burden

High level of burden

Patient is asymptomatic Symptom(s) are mild and easy to control

Any symptom is moderate and controllable

Any symptom is severe or difficult or outpatient visits, symptom crises)

Absent

Mild

Moderate

Significant

Absent
... does not cure or control but has

Medium level of burden

(0) 1. Though the two measured constructs (disease trajectory and impact on daily activities) are related, they can vary independently. Both should be scored separately.

(2) 2. Children with life-limiting conditions generally have longer disease trajectories. It is recommended that the reference baseline for Activities of Daily

(4) Living be extended to 3 months (instead of just 4 weeks) to maximise detection of change.

(0) 1. As hospital admissions are used here as a proxy for disease severity and worsening trajectory, the purpose and type of hospital stay should be considered. Elective admissions should not be included, as they could be for routine work-up (e.g. sleep studies).

2. Instead of 3 months, admissions over the last 6 months is suggested to better capture medical instability for patients with predominantly longer prognoses and variable trajectories in PPC.

(0) 1. To assess disease acuity based on potential (1) treatment options, it may be helpful to qualify with an additional statement like "treatments directed at the disease, even if not administered"; as it was observed that many patients might not have received treatments, either due to unavailability, or they were declined by caregivers.

(0) 1. It may be helpful to qualify further "Burden of treatments, both disease-directed and symptomdirected". Treatments that are not directed at the underlying disease should also be included for consideration, as they do exact a toll on the patient and caregiver (e.g. newly ventilatordependent) [28-32].

2. Burden is often contingent on the intensity and caregiver skills required to administer treatment. Points of reference should be provided to ensure agreement between assessors for each level of burden (e.g. invasive treatments should be scored as high level of burden).

(0) 1. Similar to Item 1.1, the two measured constructs to control (unplanned hospitalisation

Mild

Moderate

Significant (severity of symptoms and difficulty in

(1) management) should be scored separately, to account for differential variations.

(2) 2. The reference baseline should be extended to "within the past 3 months", to maximise detection of symptom related issues.

1. While psychological distress is inherent in complex care $[33,34]$, it may be challenging to assess this accurately as these young children may struggle to articulate distress, are noncommunicative, or cognitively impaired [33]. A proxy report - via either caregivers or the healthcare professional - is often required. If appropriate, this can be explicitly specified.

(0) 1. To be accurately evaluated, psychological distress may require professional assessment. It may be difficult for most clinicians to score distress in caregivers objectively or ensure consistency

(2) between observers in that case 
Table 4 Domain-specific observations and comments for PaPaS for assessment of patients (Continued)

\begin{tabular}{|c|c|c|c|}
\hline Domain Item & Characteristics & Score & Comments \& Recommendations (If any) \\
\hline \multirow[t]{4}{*}{ 5.1 Estimated life expectancy } & Several years & $(0)$ & \multirow{4}{*}{$\begin{array}{l}\text { 1. There is ambiguity to the terms 'weeks' and } \\
\text { 'months' as it is in the original scale. For example, } \\
\text { it is unclear whether children with a prognosis of } \\
\text { three to } 4 \text { weeks should be scored } 3 \text { or } 4 \text {. Life } \\
\text { expectancies can be better clarified using defined } \\
\text { cut-offs, e.g. "3 months to a year", "3 weeks to } 3 \\
\text { months", "less than } 3 \text { weeks". }\end{array}$} \\
\hline & Months to $1-2$ years & (1) & \\
\hline & Weeks to months Please skip 5.2 & (3) & \\
\hline & Days to weeks Please skip 5.2 & (4) & \\
\hline \multirow{2}{*}{$\begin{array}{l}5.2 \text { "Would you be surprised if this child were to } \\
\text { suddenly die in } 6 \text { months' time?" }\end{array}$} & Yes & $(0)$ & \multirow[b]{2}{*}{$\begin{array}{l}\text { 1. The word "suddenly" presents difficulty as it may } \\
\text { be challenging to determine what changes in } \\
\text { trajectories are considered sudden. It may exclude } \\
\text { patients who die after slow deterioration, even } \\
\text { within } 6 \text { months, if literally interpreted. Removing } \\
\text { the term ensures that all patients who are at-risk of } \\
\text { dying within } 6 \text { months are accounted for during } \\
\text { scoring. }\end{array}$} \\
\hline & No & $(2)$ & \\
\hline
\end{tabular}

criteria [35, 36]. Current gaps in communication, continuity of care and collaboration across settings may be minimised as a consequence.

In addition, with its strength in needs assessment, delivery of existing services may be tailored based on the $\mathrm{PaPaS}$ to meet the ever-evolving needs of patients and families who are already receiving PPC. Our study is the first to demonstrate the potential of using $\mathrm{PaPaS}$ to assess the need for continuing care; it provides a transparent and objective framework to determine which patients should continue to receive PPC.

In practice however, we have encountered cases of children being 'too well' for palliative care, despite having obvious life-shortening conditions. It is observed in borderline cases, where patients score just under 15 points. While the use of limited resources is optimised, this is an unforeseen consequence, as a quantified tool is systematically imposed.

\section{Limitations}

There are a number of factors that limit this study's conclusions. First, we did not track patients who were rejected for admission or were deemed by primary physicians not to require PPC. Hence, the ability of the $\mathrm{PaPaS}$ to identify patients unsuitable for admission to PPC cannot be commented. Moreover, the study involves a retrospective review of clinical data, which did not always map specifically to items in the PaPaS. Further research can employ prospective designs where the $\mathrm{PaPaS}$ is used directly to assess new referrals. Second, 18 of included patients in this study were below one year of age, which was excluded in the original conceptualisation of $\mathrm{PaPaS}$ due to perceived differences in needs [22]. Patients beyond 19 years of age were also included in the study. As the goal was to evaluate the utility of the $\mathrm{PaPaS}$ in identifying eligible patients for home-based PPC as established, we had included all admitted patients, regardless of age. Third, this study did not examine inter-rater reliability. Hence, potential variability in scoring between users cannot be commented. These differences may apply to attributes that are inherently not easily quantifiable, such as psychological distress. We identified this potential issue and suggested the incorporation of cues. Still, the reliability attributes of this tool should be evaluated in future reviews. The modified scale proposed here is intended to mirror the score ranges of the original instrument as much as possible. Psychometric testing of the revised scale however, is beyond the scope of this study.

Our study findings may not be generalisable to other settings outside of home-based PPC, for example, in an in-patient palliative consult service. Similarly, perceptions of monetary concerns or other related burdens can vary in contexts with different healthcare financing systems, culture, and values. Lastly, the end-user experience should also be examined in future studies, to ensure that the $\mathrm{PaPaS}$ does not create additional barriers for referrals to PPC.

\section{Conclusion}

While there are limitations in the $\mathrm{PaPaS}$ as an assessment tool for identifying patients with PPC needs, it demonstrates clear benefits for adoption within individual services and potentially the healthcare system. When deployed within a home hospice setting, the PaPaS has demonstrated positive qualities in terms of objectivity, transparency and accountability.

There is a tendency to over/under-estimate the need or even intensity of care, across different professionals and care settings. The $\mathrm{PaPaS}$ promotes greater clarity and effective handover for everyone involved, particularly at care transitions. This can lead to important outcomes like alignment of expectations 
between stakeholders, and critically, optimal case management.

Ultimately, the child and family living with lifeshortening illness is flagged in a timely manner to receive palliative care based on needs rather than prognosis, in spite of challenges posed by disease diversity and uncertain trajectories, through a process of screening that is both robust and informational, yet with cost-containing implications.

\section{Appendix}

\section{Proposed revision for the Pediatric Palliative Screening scale (PaPaS) and cut-off scores*}

\begin{tabular}{|c|c|c|c|c|c|c|c|}
\hline Domain & Item & Characteristic & Score & & or outpatient visits, & Symptom(s) are moderate & $2 \square$ \\
\hline $\begin{array}{l}\text { Domain } \\
1\end{array}$ & \multicolumn{3}{|c|}{$\begin{array}{l}\text { Trajectory of disease and impact on daily activities of the } \\
\text { child }\end{array}$} & & & $\begin{array}{l}\text { Symptom(s) are severe } \\
\text { (Please skip 3.1.2) }\end{array}$ & $4 \square$ \\
\hline \multirow[t]{8}{*}{1.1 .1} & \multirow{8}{*}{$\begin{array}{l}\text { With reference to the } \\
\text { past } 3 \text { months, the } \\
\text { disease trajectory of the } \\
\text { child, in comparison with } \\
\text { the child's own baseline, } \\
\text { is... }\end{array}$} & ...Stable & $0 \square$ & \multirow[t]{6}{*}{3.1 .2} & \multirow{6}{*}{$\begin{array}{l}\text { Difficulty of symptom } \\
\text { control over the past } \mathbf{3} \\
\text { months(consider } \\
\text { unplanned hospitalization } \\
\text { or outpatient visits, } \\
\text { symptom crises) }\end{array}$} & \multirow{2}{*}{$\begin{array}{l}\text { Symptom(s) are easy to } \\
\text { control }\end{array}$} & \multirow[t]{2}{*}{$0 \square$} \\
\hline & & \multirow{2}{*}{$\begin{array}{l}\text {...Stable, but slowly } \\
\text { deteriorating }\end{array}$} & \multirow[t]{2}{*}{$1 \square$} & & & & \\
\hline & & & & & & \multirow{2}{*}{$\begin{array}{l}\text { Symptom(s) are } \\
\text { controllable }\end{array}$} & \multirow[t]{2}{*}{$1 \square$} \\
\hline & & \multirow{2}{*}{$\begin{array}{l}\text {...Unstable with slow } \\
\text { deterioration }\end{array}$} & \multirow[t]{2}{*}{$2 \square$} & & & & \\
\hline & & & & & & \multirow{2}{*}{$\begin{array}{l}\text { Symptom(s) are difficult } \\
\text { to control }\end{array}$} & $2 \square$ \\
\hline & & \multirow{3}{*}{$\begin{array}{l}\text {...Unstable with } \\
\text { significant } \\
\text { deterioration(Please skip } \\
1.1 .2 \text { ) }\end{array}$} & \multirow[t]{3}{*}{$4 \square$} & & & & \\
\hline & & & & \multirow[t]{2}{*}{3.2} & \multirow{2}{*}{$\begin{array}{l}\text { Psychological distress of } \\
\text { patient related to } \\
\text { symptoms }\end{array}$} & Absent & $0 \square$ \\
\hline & & & & & & Mild & $1 \square$ \\
\hline \multirow[t]{5}{*}{1.1 .2} & \multirow{5}{*}{$\begin{array}{l}\text { With reference to the } \\
\text { past } 3 \text { months, the } \\
\text { impact of condition on } \\
\text { daily activities of the } \\
\text { child, in comparison with } \\
\text { the child's own baseline. }\end{array}$} & No impact & $0 \square$ & & & Moderate & $2 \square$ \\
\hline & & \multirow{2}{*}{$\begin{array}{l}\text { Daily activities are } \\
\text { impacted/restricted }\end{array}$} & 1 & \multirow{4}{*}{3.3} & & Significant & $4 \square$ \\
\hline & & & & & \multirow{4}{*}{$\begin{array}{l}\text { Psychological distress of } \\
\text { parents or family related } \\
\text { to symptoms and } \\
\text { suffering of the child }\end{array}$} & Absent & $0 \square$ \\
\hline & & \multirow{2}{*}{$\begin{array}{l}\text { Daily activities are severely } \\
\text { impacted/restricted }\end{array}$} & \multirow[t]{2}{*}{$2 \square$} & & & \multirow{2}{*}{$\begin{array}{l}\text { Mild } \\
\text { Moderate }\end{array}$} & 1 口 \\
\hline & & & & & & & $2 \square$ \\
\hline \multirow[t]{3}{*}{1.2} & \multirow{3}{*}{$\begin{array}{l}\text { In the past } 6 \text { months, } \\
\text { there was a more than } \\
50 \% \text { Increase in } \\
\text { unplanned hospital } \\
\text { admissions (compared to } \\
\text { previous periods) }\end{array}$} & No & $0 \square$ & & & Significant & $4 \square$ \\
\hline & & \multirow{2}{*}{ Yes } & $3 \square$ & $\begin{array}{l}\text { Domain } \\
4\end{array}$ & $\begin{array}{l}\text { Preferences/needs of patien } \\
\text { health professional }\end{array}$ & t or parents and Preferences & \\
\hline & & & & 4.1 & Patient/parents wish to & No & $0 \square$ \\
\hline $\begin{array}{l}\text { Domain } \\
2\end{array}$ & $\begin{array}{l}\text { Expected outcome of treatm } \\
\text { burden of treatment }\end{array}$ & nent directed at the disease & & & formulate needs that are & Yes (Please skip 4.2) & $4 \square$ \\
\hline 2.1 & Treatment directed at the & ... is curative. & $0 \square$ & & care. & & \\
\hline & $\begin{array}{l}\text { disease, even if not } \\
\text { administered }\end{array}$ & ...controls disease and & 1 & 4.2 & You/your team feel that & No & $0 \square$ \\
\hline & $\begin{array}{l}\text { include treatment of } \\
\text { disease-related complica- }\end{array}$ & $\begin{array}{l}\text { prolongs life with good } \\
\text { quality of life. }\end{array}$ & & & $\begin{array}{l}\text { this patient would benefit } \\
\text { from palliative care. }\end{array}$ & Yes & 4 \\
\hline & $\begin{array}{l}\text { tions, such as pain, dys- } \\
\text { pnea or fatigue) }\end{array}$ & $\begin{array}{l}\text {...does not cure or } \\
\text { control but has a positive }\end{array}$ & $2 \square$ & $\begin{array}{l}\text { Domain } \\
5\end{array}$ & Estimated life expectancy & & \\
\hline & & effect on quality of life. & & 5.1 & Estimated life expectancy/ & Several years & $0 \square$ \\
\hline & & $\begin{array}{l}\text {...does not control and } \\
\text { has no effect on quality of }\end{array}$ & 4 口 & & Prognosis & $1-2$ years & $1 \square$ \\
\hline & & life. & & & & $\begin{array}{l}3 \text { months to a year } \\
\text { (Please skip 5.2) }\end{array}$ & \\
\hline 2.2 & Burden of treatment, & No/minimal burden OR & $0 \square$ & & & & \\
\hline & $\begin{array}{l}\text { including both disease- } \\
\text { directed and symptom- }\end{array}$ & & & & & $\begin{array}{l}\text { Less than } 3 \text { months } \\
\text { (Please skip 5.2) }\end{array}$ & \\
\hline & $\begin{array}{l}\text { directed treatments. (con- } \\
\text { sider freauency and skills }\end{array}$ & $\begin{array}{l}\text { Low level of burden(e.g. } \\
\text { simple oral medication }\end{array}$ & 1 口 & 5.2 & Would you be surprised & Yes & $0 \square$ \\
\hline & involved; e.g. side effects, & or diet modification) & & & $\begin{array}{l}\text { if this child died in } 6 \\
\text { months' time? }\end{array}$ & No & \\
\hline & $\begin{array}{l}\text { hospital stay, additional } \\
\text { tasks for patients/ }\end{array}$ & $\begin{array}{l}\text { Medium level of } \\
\text { burden(e.g. feeding }\end{array}$ & $2 \square$ & Total Scc & & & \\
\hline
\end{tabular}

\section{Appendix (Continued)}

\begin{tabular}{lll}
\hline Domain Item & Characteristic & Score \\
\hline caregivers) & tubes, catheters, \\
& medications with \\
& adverse effects) \\
& High level of burden(e.g. $\quad 4 \square$ \\
& hospitalization, \\
& tracheostomy, BiPAP/C- \\
& PAP, PICC line, frequent \\
& suctioning)
\end{tabular}

Domain Symptom and problem burden

3

3.1.1

Symptom intensity ove

the past $\mathbf{3}$

months/consider unplanned hospitalization or outpatient visits, symptom crises) or outpatient visits, tient related to

Psychological distress of pants or family related o symptoms and suctioning)

(asymptomatic 0 (Please skip 3.1.2)

Symptom(s) are mild $\quad 1$ व

Symptom(s) are moderate 2 口

Symptom(s) are severe $\quad 4$

Symptom(s) are easy to 0 口

Symptom(s) are 1 口

Symptom(s) are difficult $\quad 2 \square$ 
${ }^{*}$ Changes from the original scale are in bold

\begin{tabular}{lll}
\hline Score & Outcome during referral & Outcome during reassessment \\
\hline$\leq 14$ & Explain goals of palliative care & For discharge \\
$\geq 15$ & Start palliative care & Continue with service \\
$\geq 25$ & Urgent need for palliative care & Continue with service \\
\hline
\end{tabular}

\section{Abbreviations}

MDT: Multi-Disciplinary Team; PaPaS: Paediatric Palliative Screening Scale; PPC: Paediatric Palliative care

\section{Acknowledgments}

Not applicable.

\section{Authors' contributions}

JS analyzed and interpreted clinical data to impute the patients' PaPaS scores; PHC provided internal validation. PHC, ZZY, RQA and CT were major contributors in writing the manuscript. All authors have read and approved the manuscript.

\section{Funding}

The authors declare that this study was not funded.

\section{Availability of data and materials}

The datasets used and/or analysed during the current study are available from the corresponding author on reasonable request.

\section{Ethics approval and consent to participate}

Ethics review was not sought from an Institutional Review Board. This study was a non-interventional, retrospective study using data that was collected as part of service provision. No information was directly collected from human participants for the conduct of this study.

\section{Consent for publication}

Not applicable.

\section{Competing interests}

The authors declare that they have no competing interests.

\section{Author details}

1HCA Hospice Care, 705 Serangoon Road, \#03-01 Block A @ Kwong Wai Shiu Hospital, Singapore 328127, Singapore. ${ }^{2}$ Ministry of Health Holdings, Singapore, Singapore.

Received: 19 July 2019 Accepted: 6 February 2020

Published online: 10 February 2020

\section{References}

1. Jünger S, Pastrana T, Pestinger M, Kern M, Zernikow B, Radbruch L. Barriers and needs in paediatric palliative home care in Germany: a qualitative interview study with professional experts. BMC Palliat Care. 2010;9(1):10.

2. Williams-Reade J, Lamson AL, Knight SM, White MB, Ballard SM, Desai PP. Paediatric palliative care: a review of needs, obstacles and the future. J Nurs Manag. 2015;23(1):4-14.

3. Chong PH, Hamsah E, Goh C. Paediatric palliative care in the Asia Pacific region: where are we now? BMJ Support Palliat Care. 2017;7(1):17-22.

4. Knapp C, Woodworth L, Wright M, Downing J, Drake R, Fowler-Kerry S, et al. Pediatric palliative care provision around the world: a systematic review. Pediatr Blood Cancer. 2011;57(3):361-8.

5. Worldwide Palliative Care Alliance. Global atlas of palliative care at the end of life: World Health Organization Website: Worldwide Palliative Care Alliance; 2014. Available from: https://www.who.int/nmh/Global_Atlas_of_ Palliative Care.pdf. Accessed 22 Apr 2019.

6. Ventura AD, Burney S, Brooker J, Fletcher J, Ricciardelli L. Home-based palliative care: a systematic literature review of the self-reported unmet needs of patients and carers. Palliat Med. 2014;28(5):391-402.
7. Miller AR, Condin CJ, McKellin WH, Shaw N, Klassen AF, Sheps S. Continuity of care for children with complex chronic health conditions: parents' perspectives. BMC Health Serv Res. 2009;9(1):242.

8. Spathis A, Harrop E, Robertshaw C, Elverson J, Lapwood S. Learning from paediatric palliative care: lessons for adult practice. Palliat Med. 2012;26(6): 777-9.

9. Wood F, Simpson S, Barnes E, Hain R. Disease trajectories and ACT/RCPCH categories in paediatric palliative care. Palliat Med. 2010;24(8):796-806.

10. Fraser LK, Lidstone $V$, Miller M, Aldridge J, Norman P, McKinney PA, et al. Patterns of diagnoses among children and young adults with life-limiting conditions: a secondary analysis of a national dataset. Palliat Med. 2014; 28(6):513-20.

11. Lindley LC, Lyon ME. A profile of children with complex chronic conditions at end of life among Medicaid beneficiaries: implications for health care reform. J Palliat Med. 2013;16(11):1388-93.

12. Feudtner C, Kang TI, Hexem KR, Friedrichsdorf SJ, Osenga K, Siden H, et al. Pediatric palliative care patients: a prospective multicenter cohort study. Pediatrics. 2011;127(6):1094-101.

13. Lidstone $\mathrm{V}$. The role of hospices in supporting young people in transition from children to adult services. London: Help the Hospices Commission; 2013.

14. Taylor LK, Miller M, Joffe T, Parslow RC, Aldridge J, Bailey CC, et al. Palliative care in Yorkshire, UK 1987-2008: survival and mortality in a hospice. Arch Dis Child. 2010;95(2):89-93.

15. Inglin S, Hornung R, Bergstraesser E. Palliative care for children and adolescents in Switzerland: a needs analysis across three diagnostic groups. Eur J Pediatr. 2011:170(8):1031-8.

16. Brook LA, Kerr C, Hawker S. Defining children who may have palliative care needs: a delphi consensus building study. Arch Dis Child. 2011;96(Suppl 1):A79.

17. European Association for Palliative Care. IMPaCCT: standards for paediatric palliative care in Europe. Eur Jour Pall Car. 2007:14(3):109-14.

18. Friebert $S$, Osenga K. Pediatric palliative care referral criteria. In: Pediatric palliative care referral criteria. Center to Advance Palliative Care. 2009. https://www.capc.org/documents/288/. Accessed 31 Jan 2020.

19. Harrop E, Edwards C. How and when to refer a child for specialist paediatric palliative care. Arch Dis Child Educ Pract Ed. 2013;98(6):202.

20. Burke $\mathrm{K}$, Coombes LH, Menezes A, Anderson AK. The 'surprise' question in paediatric palliative care: a prospective cohort study. Palliat Med. 2018;32(2): $535-42$

21. Shaw KL, Brook L, Mpundu-Kaambwa C, Harris N, Lapwood S, Randall D. The Spectrum of Children's palliative care needs: a classification framework for children with life-limiting or life-threatening conditions. BMJ Support Palliat Care. 2015:5(3):249-58.

22. Bergstraesser $E_{1}$ Hain RD, Pereira JL. The development of an instrument that can identify children with palliative care needs: the Paediatric palliative screening scale (PaPaS scale): a qualitative study approach. BMC Palliat Care. 2013;12(1):20

23. Bergstraesser E, Paul M, Rufibach K, Hain RD, Held L. The Paediatric palliative screening scale: further validity testing. Palliat Med. 2014;28(6):530-3.

24. Bossuyt PM, Reitsma JB, Bruns DE, Gatsonis CA, Glasziou PP, Irwig L, et al. STARD 2015: an updated list of essential items for reporting diagnostic accuracy studies. BMJ. 2015:351:h5527.

25. Thompson LA, Knapp C, Madden V, Shenkman E. Pediatricians' perceptions of and preferred timing for pediatric palliative care. Pediatrics. 2009;123(5): e777-e82.

26. Weissman DE, Meier DE. Identifying patients in need of a palliative care assessment in the hospital setting: a consensus report from the center to advance palliative care. J Palliat Med. 2010;14(1):17-23.

27. Chong PH, De Castro Molina JA, Teo K, Tan WS. Paediatric palliative care improves patient outcomes and reduces healthcare costs: evaluation of a home-based program. BMC Palliat Care. 2018;17(1):11.

28. de Souza EJ, da Silva LF, Santos da Conceicao D, Dorea Paiva E. Families' concerns about the care of children with technology-dependent special health care needs. Invest Educ Enferm. 2015;33(3):547-55.

29. Meltzer LJ, Mindell JA. Impact of a child's chronic illness on maternal sleep and daytime functioning. Arch Intern Med. 2006;166(16):1749-55.

30. Moskowitz JT, Butensky E, Harmatz P, Vichinsky E, Heyman MB, Acree M, et al. Caregiving time in sickle cell disease: psychological effects in maternal caregivers. Pediatr Blood Cancer. 2007:48(1):64-71.

31. Raina P, O'Donnell M, Rosenbaum P, Brehaut J, Walter SD, Russell D, et al. The health and well-being of caregivers of children with cerebral palsy. Pediatrics. 2005;115(6):e626-36 
32. Toly VB, Musil CM, Carl JC. Families with children who are technology dependent: normalization and family functioning. West J Nurs Res. 2012 34(1):52-71.

33. Cadman D, Rosenbaum P, Boyle M, Offord DR. Children with chronic illness: family and parent demographic characteristics and psychosocial adjustment. Pediatrics. 1991;87(6):884.

34. Perrin JM, Gnanasekaran S, Delahaye J. Psychological aspects of chronic health conditions. Pediatr Rev. 2012;33(3):99-109.

35. Chong PH. What do physicians think about paediatric palliative care? A survey in Singapore. Eur Jour Pall Car. 2014;21(2):93-7.

36. Twamley K, Craig F, Kelly P, Hollowell DR, Mendoza P, Bluebond-Langner M. Underlying barriers to referral to paediatric palliative care services: knowledge and attitudes of health care professionals in a paediatric tertiary care Centre in the United Kingdom. J Child Health Care. 2013;18(1):19-30.

\section{Publisher's Note}

Springer Nature remains neutral with regard to jurisdictional claims in published maps and institutional affiliations.

Ready to submit your research? Choose BMC and benefit from:

- fast, convenient online submission

- thorough peer review by experienced researchers in your field

- rapid publication on acceptance

- support for research data, including large and complex data types

- gold Open Access which fosters wider collaboration and increased citations

- maximum visibility for your research: over $100 \mathrm{M}$ website views per year

At $\mathrm{BMC}$, research is always in progress.

Learn more biomedcentral.com/submissions 